\title{
ENGENDERED REPRESENTATIONS: EXPLORING SEXUALITY THROUGH SYMBOLS AND MYTHS
}

Authors:

Rory du Plessis ${ }^{1}$

Marinda Maree ${ }^{1}$

\section{Affiliations:}

${ }^{1}$ Institute for Women's and Gender Studies, University of Pretoria, South Africa

\section{Correspondence to:}

Rory du Plessis

e-mail:

rory.duplessis@up.ac.za

\section{Postal address:}

Institute for Women's

and Gender Studies,

Humanities Building 20-

17, University of Pretoria,

Pretoria, 0002, South Africa

\section{Keywords:}

gender; patriarchy; sperm; semen; symbolism; sexuality

\section{Dates:}

Received: 04 Mar. 2009

Accepted: 21 Apr. 2009

Published: 04 Sept. 2009

How to cite this article: Du Plessis, R. \& Maree, M., 2009, 'Engendered Representations: Exploring Sexuality through Symbols and Myths', Verbum et Ecclesia 30(2), Art. \#55, 6 pages. DOI: $10.4102 /$ ve.v30i2.55

\section{This article is available} at:

http://www.ve.org.za
(C) 2009. The Authors. Licensee: OpenJournals Publishing. This work is licensed under the Creative Commons Attribution License.

\section{ABSTRACT}

This article reflects the findings of a project that was conducted by the Institute for Women's and Gender Studies at the University of Pretoria. In particular, the project sought to dialogue with religious and cultural leaders on the taboos, myths and misconceptions of human sexuality. The article provides an analysis of the symbols and myths of sexuality that were presented by these leaders. These symbols and myths were demystified to reveal their alignment to patriarchal gender divisions and inequality. This alignment proves problematic for women, as it views men as possessors of their bodies - insofar as women's bodies are conceived as the vessels for men's body fluids and the container of the foetus.

\section{INTRODUCTION}

This paper aims to discuss the symbols and myths that are used to represent sexuality with reference to a project spearheaded by the Institute for Women's and Gender Studies at the University of Pretoria entitled Religious and cultural perspectives of human sexuality.

In particular, this project, which was conducted between 2006 and 2007, aimed to explore and debate key issues of human sexuality with religious and cultural leaders from the urban and semi-urban areas that surround Tshwane in the province of Gauteng in South Africa. The project took the form of a series of workshops in which the identified participants (religious and cultural leaders) from the given communities dialogued the key issues of human sexuality - the taboos, myths and misconceptions that give rise to the increased vulnerability of HIV infection among their community members.

This article presents an analysis of the symbols and myths presented by the participants at the project's workshops ${ }^{1}$.

This article first gives a background to the project. The background identifies the relationship between gender divisions and HIV infection and provides a framework to contextualise the findings of the project. These findings were initially documented by the focus groups that informed the project's workshops. Discussions on the study of sexuality and on the very nature of symbols and myths are then highlighted, after which the analysis is provided. The culminating analysis of the representation of sexuality through symbols and myths is limited to that of sperm, which is saliently demonstrated to reveal patriarchal descriptions of sexuality - male virility and female passivity and/or receptivity.

\section{BACKGROUND}

The motivating factor for embarking upon the previously mentioned project was the recognition that, although religious and cultural leaders are influential in their respective communities, many are ill prepared to discuss matters relating to human sexuality. Most of these leaders are not, to a large extent, equipped with knowledge and skills related to key areas of healthy human sexuality. Certain unhelpful attitudes and teachings furthermore continue within these communities even though these very same attitudes are shown to increase the risk of HIV infection among the members of the communities.

This overarching factor established the project's target group: leaders and members of religious and cultural groups who inform the perspectives and positions of their communities in relation to human sexuality. The parameters of the target group were restricted to communities in the greater Tshwane region.

Individuals express their sexuality in a variety of ways that are determined to a significant extent by the messages, teachings, views and perspectives of religious and cultural leaders within their communities. The aim of the project was thus to provide these leaders with skills and knowledge to inform their understanding of human sexuality. This would, in turn, enable them to provide their communities with leadership on matters of responsible and informed sexual decision-making and, ultimately, contribute towards reducing the vulnerability of their community members to sexually transmitted infections, especially HIV/AIDS.

To achieve this aim, the project created a structured dialogue process to explore human sexuality. These dialogues enabled the identified leaders to explore the ways in which social and cultural environments shape or construct sexuality and the ways in which human sexuality continues to be affected by the legacies of colonialism, apartheid, the historical influence of missionaries and the migrant-labour system, as well as by urbanisation and globalisation. The dialogues also promoted sexual literacy and access to accurate sexual education as both a right and a norm.

1.This article is limited to the investigation into the symbols and myths (both African and Western) presented by the participants. It does not include an investigation into the interface of religion, myths and sexuality. For discussions on religion and sexuality in Africa, see Maticka-Tyndale, Tiemoko \& Makinwa-Adebusoye (2007). 
The project's dialogues were based on the fact that the country is culturally diverse and that this influences how individuals express their sexuality. The project therefore promoted the values that underpin the South African Constitution: the prohibition of all forms of discrimination and the protection and promotion of the rights of individuals, especially of their sexual rights. As such, the project improved the understanding of human sexuality among different communities while simultaneously forging an awareness of and respect for people with different sexual values.

However, informing leaders with knowledge of human sexuality is in itself not sufficient to bring about a change in perspective Information must also be linked to culturally appropriate notions of sexuality, of social and sexual relations and of gender relations and identities. Information must furthermore impact on the culturally collective values that perpetuate unequal social relations - the privileging of men in sex relations that limits women's ability to choose safer sexual practices or to refuse sexual activity. The outcomes of the workshop therefore moved beyond traditional notions of knowledge dissemination to include the following aspects:

- Exploring existing perceptions, conventions and myths in relation to masculinity and femininity.

- Identifying aspects of gender behaviour that evoke risk and harm.

- Making men aware of their social power and of the dangers to both men and women of its exercise and making women aware of how they collude to reinforce male power.

- Challenging men and women to redefine their masculinity and femininity so that they are able to express their own sexual desires, to manage risks and to insist on their own safety and equality.

- Creating a positive conception of the possibilities of sex as both enjoyable and safe, so that both men and women can communicate what they want and resist sex on other terms.

The outcomes of the workshop therefore included emphasis on the unique elements of women's lives, elements that are too often ignored or overshadowed when women's issues are subsumed under patriarchal approaches to history, culture, civil rights, access to resources and political decision-making. The outcomes also acknowledged the need to continue addressing issues of gender: the broader socio-cultural constructs that enculturate men and women into stereotypical and restrictive roles, attitudes and aspirations and that impose differences in power, and authority and access to resources based on the sex of an individual.

Through these outcomes, the project's dialogues on human sexuality ensured that the participants could not only dispel myths regarding sexuality but also recognise the gendered implication of such belief structures.

\section{LITERATURE REVIEW}

The past few decades have seen increasing interest in sexuality across a wide array of disciplines. This can be attributed in part to the fact that, since the emergence of HIV/AIDS, issues such as sexual health and the need to provide for what were previously viewed as private issues between individuals have entered the public sphere. $^{2}$ The HIV pandemic has thus contributed to a process in which sex has become very visible (Posel 2005a; Posel 2005b; Reid \& Walker 2005; Serrant-Green 2005:513). Sexuality in the public sphere, however, has been marred by sexual controversies (rape, HIV infection, molestation and abuse), which have immersed sexual dialogues in a wider matrix of

2.For example, to curb the spread of HIVIAIDS, widespread and very explicit advertising around the negotiating of sex and safer sexual practices is channeled advertising around the throu hiDS has asso become an integral part of soap-opa oap-opera plots (/sidingo) and media events (the 46664 Concert). moral anxiety, social instability and public contestation. ${ }^{3}$ Amid this public pathologisation of sexuality, the definition of sexual health by the World Health Organisation (WHO) has moved away from these narrow approaches of sexuality to considering how sexuality is interconnected with our daily lives and health and to including a positive and pleasurable conception of sexuality. The definition of sexual health by WHO is viewed as follows:

A state of physical, emotional, mental and social well-being related to sexuality; it is not merely the absence of disease, dysfunctions or infirmity. Sexual health requires a positive and respectful approach to sexuality and relationships, as well as the possibility of having pleasurable and safe sexual experiences, free of coercion, discrimination and violence. For sexual health to be attained and maintained, the sexual rights of all persons must be respected, protected and fulfilled.

(WHO 2008)

In this definition, sexual health refers to the ability to express sexuality free from the risk of sexually transmitted infection, unwanted pregnancy, coercion, violence and discrimination. It includes the right to an informed, enjoyable and safer sex life based on a positive approach to sexual expression and mutual respect in sexual relations. Sex and sexuality are thus no longer viewed as a physical act or drive but as immersed in society, culture and gender relations.

The possibilities for positive and pleasurable conceptions of sexuality, however, are marred by issues of gender inequality, which can increase vulnerability to HIV infection. A full description of gender inequality as a vehicle or transmission route for HIV infection is outlined below.

Specific focus on gender reveals startling findings such as the fact that $56 \%$ of all HIV adult infections in South Africa are female (UNAIDS 2006:455). Additionally, the HIV prevalence rate in South Africa is $14.5 \%$ for men and $21.8 \%$ for women (UNFPA 2008).

This implies that, to understand the differences between the infection rates of women and men, an analysis of HIV should move beyond the health sector to recognise the complex ways in which biology and social factors interact with one another and result in the exacerbation of the biological vulnerability of women's bodies to HIV (Van der Kwaak \& Dasgupta 2006). Furthermore, women's vulnerability to HIV/AIDS is increased by societies that subordinate and marginalise their access to resources and knowledge. Women's marginalised status can mean that they have less power to negotiate sexual and reproductive health matters, less economic independence, less education and less access to health care. Thus, the current trends of HIV transmission and prevalence clearly reflect that the epidemic is fuelled by gender-based vulnerability. Taking this into consideration, it is clear that the mainstreaming of gender within sexual-health research should become integral in the attempt to curb the further spread of the epidemic (Van der Kwaak \& Dasgupta 2006).

The spread of HIV/AIDS is significantly related to the position of men in gender relations, more specifically to misogynistic and heterosexual masculinity (Morrell 2001:31). In most gender systems, men have predominant control in sexual relations. Men who hold gender ideologies that prioritise men's pleasure over women's or that assume that men have rights to the bodies of women increase the vulnerability of women to HIV infection and negate the efforts of women to negotiate safer sex practices (Kometsi 2004:10). Thus, the fact that a man is far more likely than a woman to initiate, dominate and control sexual

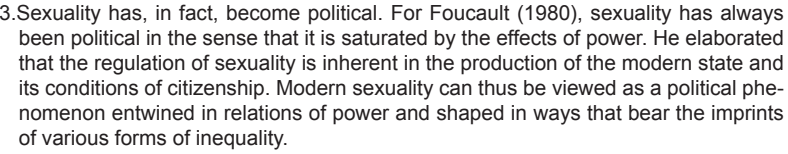


interaction creates a tremendous barrier to the ability of women to adopt HIV risk-reducing behaviour. Additionally, this position of sexual power is often associated with a dominant (hegemonic) masculinity that values risk-taking or that sees virility as a measure of a man's worth (Connell 2003:16). In such hegemonic markers of masculinity - those that prize virility, sexual voraciousness and multiple sexual partners to prove manhood - all become contributors to the spread of HIV (Sorrell \& Raffaelli 2005:593; Sternberg 2000:89).

These findings suggest both direct and indirect linkages between the gendered notions of masculinity and femininity and HIV/AIDS infection. The findings also highlight the need for prevention efforts that focus on the provision of alternative avenues to attain culturally recognised markers of gender and gender relations (Sorrell \& Raffaelli 2005:585).

\section{METHOD}

As stated previously, the research reported in this article was documented in a series of workshops that formed part of the Religious and cultural perspectives of human sexuality project. Religious and cultural leaders from urban and semi-urban areas of Tshwane, such as Garankuwa, Hebron, Kgoma-Kgoma, Mabopane and Soshanguve, were the predominant participants in the project's workshops. In total, there were 46 participants, of which $21(46 \%)$ were male and 25 (54\%) were female. Their ages varied between 23 and 65 years (the average age being 40 years). In particular, the participants were community and religious leaders involved in home-based care, youth work and HIV/AIDS counselling. Several religious groups and affiliations were represented, namely the Apostolic Faith Mission, the Roman Catholic Church, the Christian Fellowship Church, the Baptist Church, the Greek Orthodox Church and Jehovah's Witnesses.

\section{Research design}

The project entailed two five-day workshops during which discussions and dialogues on sexual beliefs were explored. Several discussion groups were conducted within each workshop, the discussions taking the form of focus groups of five to seven participants. The focus groups reflected the composition of the sample to a large extent in terms of its religious-affiliation, age and gender composition. Focus groups are a way mainly to collect data and, in this instance, they formed part of the action research. Action research aims to stimulate groups of people to change (Reinharz 1992). In terms of this project, the action research was deployed to bring about transformation on sexual beliefs that endanger both women and men in respect of sexual abuse and HIV infection. For the purposes of this article, however, focus was not on the process of change, as such, but on the reporting of the representations of sexual beliefs. The research design for this article was therefore based on the outcomes of the focus groups.

The utilisation of focus groups in the project was useful because it facilitated the collection of qualitative data within a naturalistic context; participants had the opportunity to voice opinions, debate and criticise (Wilkinson 2003). To foster this approach, the workshops were based on certain agreed-upon ground rules, such as allowing for the voicing of opinions and respect for various and dissimilar opinions. In this way, an atmosphere of sharing and openness was created. The fact that the meaning of sexual belief is revealed only through context was also acknowledged. Focus groups are favoured as a research tool, as they afford for the contextualisation and facilitation of social process in which the creation of meaning is made (Wilkinson 2004).

\section{Data collection}

The proceedings of the focus groups were documented by a rapporteur. Although the sessions were not videotaped, as is normal practice with focus groups, one should keep in mind that the purpose of the focus groups was to facilitate discussion within the process of a workshop. The workshops were based on adult educational methods and active learning methods that consisted of case studies, reflective exercises, small-group presentations and practical assignments. These documented focus groups were analysed through thematic analysis: themes were identified and discussed. For the purposes of this article, the themes were interpreted within a constructionist context (Wilkinson 2003). This means that the theme (a myth, a symbol or a particular understanding of sexual practices) can be seen as a cultural construct created within a culture that accords it with a specific meaning.

\section{DISCUSSION}

In discussions on sexuality, sexuality tends to be pivoted on the assumption that the sexual act is a definable and a universal experience. This assumption is problematic, as it ignores the great variety of cultural patterns revealed by history and the very different meanings given to sexual activity (Weeks 1989:1). Thus, rather than sexuality being an essentially human quality known through all time, sexuality is a historical construction (Bristow 1997:5; Laqueur 1992), ${ }^{4}$ that cannot be isolated from its discursive, socially determined milieu (Bhattacharyya 2002:39).

However, research on African sexuality has tended to view sexuality as static and ahistorical rather than dynamic and subject to change (Reid \& Walker 2005). The implication of this is not only that colonial images and stereotypes are manifest in discourses on African sexuality but also that these myths of sexuality become framed and eternally essentialised. The implication of envisaging African 'tradition' as fixed culminates in the conviction that there is no power to resist these myths and that the myths are unchanging (that they do not and cannot reflect contemporary influences). This framing of the concept of 'tradition' masks the flexibility of cultural constructions of identity and the porousness and mutability of traditions. Thus, rather than positing a binary of African versus Western, the myths and symbols discussed in this analysis seek to expose contemporary beliefs (whether African or Western) as sharing a patriarchal scripting of sexuality and gender roles.

Fundamental to this paper and the previously mentioned readings is that research into sexuality is extended to move beyond sexual practices to include the beliefs, perceptions and representations of sexuality in all their cultural and historical variety. In this light, traditional scientific methods of sexual research, such as epidemiological methods of the conceptualisation and quantification of sexuality, do not allow for an understanding of the meanings associated with sexuality. Research on sexuality is therefore moving beyond a statistical reading of sexual health to explore the mechanisms and symbols of sexuality, a move from studying the sex act to positioning sexual behaviour within its cultural settings. These cultural settings act as systems of classification that structure and define sexual experience in different social and cultural contexts (Peltzer 2006; Shoveller \& Johnson 2006).

Researchers on sexuality are therefore implored to devote more attention to the social formation and representation of sexual mores, since the adoption of such an approach reveals the relationship between sexual fantasies and sexual modes of behaviour or the connection between social circumstances and sexual practices (Hekma 1991:188).

4.For Foucault (1980), sexuality is not an obstinate drive that is by its very nature defiant to power but rather a historical construct that acts as a transfer point of the relations of power, a surface network in which the body becomes linked to discourses and strategies of knowledge and power (Foucault 1980:105-106). Thus, the importance accredited to Foucault's work is that he posited sex within the context of the institutions and history in which it evolves. In other words, he allowed for text of the insticcrod sex to be viewd as relotion it. This, in turn, demands an exploration of various forces that have shaped and constructed 'sexuality', such as gender, religion, class and power relations. 
In studies regarding the symbols and myths of sexuality, the (gendered) body proves to be a crucial reference point. Douglas believed that the human body provides the basic scheme for all symbolism, which, in turn, reflects complex social forms. These bodily symbols located in and on the body represent socio-cultural markers mirroring the hierarchy of a given social system (Douglas 2004:4). In this sense, the social body (read as 'social system') constrains the way in which the physical body is perceived. The physical experience of the body is thus modified by the social categories through which it is known. This is what sustains a particular view of society. There is a continual exchange of meaning between these two kinds of bodily experiences so that each reinforces the categories of the other.

This model is manifest in the dominant formation of female and male physiology as equivalent to a vessel that is cautioned not to pour away or dilute its vital fluids. In this arrangement, females are seen literally as the entry point of the male's 'pure content' (semen) and, as counterfoil to this, men are seen as pores through which sperm is released (Douglas 2004:156). This configuration restricts the medium of the body to an expression of patriarchal ideology. It establishes sexuality in a singular (male) form that is preoccupied by the 'rightful' and highly prized deposit of sperm in its resting place - females. The corollary of this notion is that female sexuality and body morphology are established as male-orientated, defined in terms of male needs (Grosz 1994:228; Myerson 1986:68). This phallocentric formation is inadequate in accounting for the diversity of sexuality - its practices, acts, behaviours and desires - for both women and men. Like sexuality, the body is not an ahistorical, a precultural or a natural object but the fluids and sexual expression, the drives and pleasures of the body are mediated by cultural representations, models and images that are guided by dominant ideologies. The body (and its fluids, practices and behaviour) is a central locus and metaphor for the understanding and exploration of discussions on sexuality (Mirzoeff 1995:2)

By recognising these key insights on sexuality, the following analysis of the project's findings are pivoted on a core framework that recognises the following: (1) Sexuality is not a biological constant but an ever-changing phenomenon. This means that studies in sexuality should not pay attention only to social, economic or religious sides of sexuality but also to the symbols and myths that categorise the 'architecture' of sexuality. (2) The study of sexuality through symbols and myths does not frame African beliefs as separate but describes them as one manifestation (along with Western myths) as a reflection of contemporary patriarchal views on gender and gender relations. (3) The body provides a scheme for all symbolism that reflects the hierarchy of the social system. As such, our access to our very own drives and expressions are mediated by representations that are ideologically motivated. Thus, in sum, these points provide a framework for the subsequent analysis of the symbols and myths of sexuality: rather than exclusively conceptualised as a biological drive, a neutral surface, sexuality is argued to be constituted through cultural practices. These cultural practices manifest symbols and myths that legitimate, construct and perpetuate patriarchal prescriptions of sexuality through functioning as models of sexual behaviour and acts.

\section{ANALYSIS}

Although the project identified several key topics (menstruation, semenarche, circumcision, virginity-testing, masturbation and sexual orientation) for discussion and debate, the following analysis is limited to the representation of sperm as identified by the participants.

Although there are distinct differences between sperm and semen (sperm constitutes only between $2 \%$ to $5 \%$ of semen, the rest of the semen being composed of fluid from the seminal vesicles and prostrate), in the discussions on semen, sperm was separated from semen and anthropomorphised, that is given human qualities (Moore 2007:5). In this light, sperm becomes an extension of masculinity and of gender stereotypes: sperm (man) is strong, while the ovum (woman) is passive. Thus, sperm is a liminal substance as it traffics between biological and social worlds; in terms of biology, it is required for fertilisation but this scientific knowledge is socially filtered to reveal patriarchal descriptions of gender and sexuality that assign meanings to sperm (Moore 2007:12)

Sperm is layered with meanings related to both the public and the private realms of human sexuality, reproduction, health and illness, masculinity and femininity. These layered attributes to the meaning of sperm permit Moore to term our understanding of sperm as 'polyspermous' (Moore 2007:5). That being said, the analysis that follows traces the diverse social and cultural representations of sperm situated within the project's findings. However, no matter how diverse and 'polyspermous' these representations are, they are all described as a manifestation of patriarchy, as a substance linked to hegemonic masculinity and phallic attributes. ${ }^{5}$

\section{Venting virility: Sperm as a sign of manhood and male sexuality}

Sperm was described by the participants as 'a sign of manhood'. This seemingly innocent account, however, carries an ideological impetus. This ideology was revealed in later discussions in which the participants explained that, if a man does not make a woman pregnant, he is deemed to have weak sperm, that the 'man is giving Sprite not inkomazi'. ${ }^{6}$ In this sense, the relationship between a man and his semen is anthropomorphised to an affinity between the cells and the man who produces the sperm (Moore 2007:139). In other words, men represent sperm as a projection of the man that produces the sperm and these projections are measured according to hegemonic descriptions of manhood: as virulent and dominant in sexual schemas (Moore 2007:139, 148). Thus, in regard to the quote in question, the sperm's inability to impregnate a woman becomes a projection onto the man that produces the sperm and his masculinity becomes dubious.

Continuing with the preceding findings, participants identified that if one is not sexually active, the sperm will travel in the bloodstream to an individual's brain and make him mad'. This view corresponds with what van Dyk (2001) identified as a principal African belief, in which the blockage of the natural flow of the body's fluids is believed to be an inevitable cause of illness that can even be fatal (van Dyk 2001:63).

Such a belief, however, is not unique to Africa. It is also manifest in Western accounts in which sperm (like testosterone and penises) is similarly portrayed as a powerful force by which men are driven to certain (sexual) acts that are beyond their control,

5.It is imperative to note that both female and male participants provided statements akin to patriarchal formations. Irigaray (1985) described that even female eroticism and sexuality are conceptualised according to the masculine parameters of a desire in which female sexuality becomes an obliging prop for male fantasies and sexuality.

6.In this description, semen deemed to be fertile is depicted as milky, thick and white and thus akin to Inkomazi (a South African full-cream, cultured milk). Conversely, infertile semen is depicted as a tran arent liquid (like Sprite, a lemonade-flavoured in fluids of men (as milky and thick) from the perceived fluidity of women (as liquid). Furthermore, sperm (rather than semen) is represented primarily through what it makes (a foetus) and what it achieves (male virility). In addition, in this sense, its fluidity and potential seepage are perpetually displaced by discourses that construct it as an object (Grosz 1994:199). Irigaray (1985) sees this conception of a fluid (semen) as a solid (sperm), as the establishment of a boundary that congeals - phallicises - male flows, which usually link male bodies to the modes of representation that are commonly attributed to female bodies (Grosz 1994:199). In regard to the quote, the reading implies that an infertile man is relegated to the In regard to the same frame of reference as a women, as expressing a seepage (due to infertile sperm, semen remains fluid and cannot be phallicised, as it serves no inherent or
procreative function). 
hence men not being wholly responsible for such acts (Moore 2007:152). These sentiments were revealed in the 2008 July to September issue of Intimacy, ${ }^{7}$ in which the article Do you refuse to have sex? (2008:30-35) discussed the common perception that men are believed to have a higher sex drive than the average woman ${ }^{8}$. It is troubling enough that this perception was taken as common fact within the article but even more troubling are the gendered implications of this perception. The unquestionable 'truth' of a man's high sex drive is seen to amount to strong sexual urges, culminating in him taking sexual risks (despite the consequences), being unfaithful and/or frequenting prostitutes. In this equation, women are implored to satisfy the sexual urges of their male partners. Women are also cautioned against being 'gate-keepers' to sex and are warned that this may lead to negative consequences, such as male partners losing their sex drive or, conversely, seeking sex elsewhere.

The findings showed throughout that both African and Wester $\mathrm{n}$ beliefs reveal a portrayal of male sexuality that is biologically determined and an instinctual drive akin to hydraulic pressure that must be expressed and released (no matter the consequences of such actions). The corollary of this is that sex in this framework cannot be a consensual or negotiable act; women are mere passive vessels for the release (receiving) of the male sex drive.

\section{Reproduction as male: The sole procreative function of semen}

Further discussions on sperm saw the participants define it in terms of its reproductive capacity in that it is important for producing babies' and that 'one drop can make a child'. A more pervasive thought was later revealed in which the participants marvelled at the powerful agency and self-contained role in reproduction of sperm cells. This was evident in descriptions such as 'It [sperm] is a life-giving capacity limited to men alone'. Although theorists have explored the African beliefs of the value of women being determined by their fertility (van Dyk 2001:64), there have been few substantial studies on the very same fertility of women as dependent on the procreative potential of men - their semen. This concept is illustrated in some African beliefs that repeated contributions of semen are needed to ripen the growing foetus in the womb and that semen is believed to contain important vitamins that are necessary not only for the continued physical and mental health of women but also for their beauty and future fertility (Van Dyk 2001:64).

The belief of the crucial and even exclusive role of men in human reproduction, in which women are deemed mere vessels for carrying the foetus, is evident not only in African belief; it may even be described as a hallmark of Western thought since its origin. The basis of many Western cultural notions about conception and sexual reproduction came from a theory by Aristotle (fourth century BC), in which he posited different roles for men and for women. This gave political connotation to ideas about sex and reproduction from which we have not yet fully escaped. Aristotle believed that the male was the major factor in reproduction and that the female only provided the material for the semen to work upon (Bordo 1999:246). ${ }^{9}$ Contemporary expressions of the marginalisation of the generative or

7.Intimacy is described as 'a unique magazine that addresses intimacy within the context of marriage, for the first time ever information that was previously taboo is for ( (Fernandez 2008).

8. The 'science' of such a claim proves problematic, as it has been revealed that the medical, chemical and biological analyses of bodies do not show absolute truths but show, instead, that the 'truths' of such 'science' are guided by the prevailing ideologies of the epoch concerned (Laqueur 1992:43). Investigations such as these therefore serve only to naturalise dominant social relations (Moore 2007:13).

9. Historically, Aristotle is heralded as the most influential pre-modern author on human sexul activity and is widely regarded as the founder of Western sexology (Bullough 1994:9). Aristotle's theory that 1994.9). Anistotle's heory that women's only part in conception was merely to supply a container in which 'seed'grows was refuted only in the 16 h century AD. Fo further discussions on Aristotle and the gendered implications of his claims, see Laqueur (1992). reproductive capacity of women have been discussed at length by several authors (Hanafin 2009; Moore 2007; Sharpe \& Faulkner 2008).$^{10}$ All these authors have discussed extensively how sperm becomes linguistically scripted to fulfil the patriarchal visions of the marginalisation of the reproductive potential of women. Women are represented as a transitional site for the production of a life that is ultimately generated by the fathers. The fact that the role of women in reproduction and birth is bypassed in this schema allows males to claim themselves to be the fount of all life (Hanafin 2008).

With sperm symbolised as singularly responsible for reproduction in both African and Western beliefs and combined with the previous thoughts on the anthropomorphisation of sperm, the resounding reading reveals patriarchal visions and ideals: sperm is not only the lone driver of human sexuality but it also positions men as being in control of human reproduction. Sperm is seen to commandeer men's bodies while simultaneously compelling men to behave in particular ways. Furthermore, by marking sperm with the traits of hegemonic masculinity, these behaviours are naturalised and legitimated (Moore 2007:31-37).

\section{Negating safer sexual practices}

In the context of HIV/AIDS, ways of having sex that are nonpenetrative in nature are encouraged to reduce infection rates. However, certain attitudes towards these interfere with their adoption as 'legitimate' ways of having sex (Kometsi 2004:32). The previously mentioned analysis of sperm revealed that the issues impacting on safer sexual practices include male virility (high-risk sexual activity as validated by a sex drive that requires release) and the important role allotted to sperm (exemplified in the refusal to wear a condom, as its usage is deemed to avert the 'natural' flows of sperm and its 'natural' resting place in a woman's body). These are both markers and beliefs that, whether contemporary or historical, 'African' or 'Western', validate male privilege and power and negate the use of condoms (and the efforts by women to negotiate safer sexual practices).

\section{CONCLUSION}

Throughout the preceding discussions, the central motivating factor has been that it is imperative to analyse the social structures that shape and influence sexuality. This goal was approached through the demystification of the symbols and myths of human sexuality to reveal the alignment of sexuality to patriarchal gender divisions. As such, the study is a critical analysis that resists and challenges naturalist and essentialist beliefs regarding human sexuality that ensure the maintenance and reproduction of male supremacy.

To address these factors, analysis of symbols and myths was limited to that of the representation of sperm as revealed through the participants in the project's workshops. Their understanding of sperm was revealed to be constructed through representations that drew upon gendered beliefs and ideologies. Although sperm does come from male bodies, sperm are not men; they are not gendered and neither are they sentient beings with emotions and personalities (Moore 2007:69). However, the expressions and meanings of sperm gleaned from the analysis reveal that sperm is represented in accordance with patriarchal gender divisions and inequality; the meaning is always to reinforce a sense of virile masculinity. This conception proves problematic for both gender and sexuality, as it valorises virile male sexuality as a potent drive that must constantly be

10.In terms of psychoanalytic discourse, Horney theorised the marginalisation of the generative or reproductive capacity of women as 'womb-envy'. This term is used to explain the envy that both boys and men have of women. Their 'wombenvy', according to Horney, is the psychological driving force behind the creation of the acording to Honey, is the psychological driving force benind the creation of this by devaluing women and their maternity and by over-valuing male creative generation and male genitalia (Berger 1994; Sayers 1986:37-38). 
'quenched' while simultaneously viewing women as a mere outlet for the male sex drive and/or as a vessel for carrying a foetus. Thus, by anthropomorphising sperm in our beliefs and practices, symbols and myths, we institutionalise gender inequalities.

In regard to the project, by exposing such inherent gender inequality in the dominant symbols and myths of human sexuality, the workshop's participants were exposed to a model of sexuality that reflects and promotes the interests of men: sex defined in male terms and thus facilitating the sexual-political control of women by men. Beyond this, the project also offered empowerment through a positive conception of sexuality in which sex is both enjoyable and safe, an expression of sexuality that is redefined to respect communication between sexual partners, to reclaim rights to the body and to insist on safety and equality.

\section{REFERENCES}

Berger, M.M. (ed.), 1994, Women beyond Freud. New concepts of feminine psychology, Brunner/Mazel, New York.

Bordo, S., 1999, The male body. A new look at men in public and private, FSG, New York.

Bhattacharyya, G., 2002, Sexuality and society. An introduction, Routledge, New York.

Bremmer, J. (ed.), 1991, From Sappho to de Sade. Moments in the history of sexuality, Routledge, London.

Bristow, J., 1997, Sexuality, Routledge, New York.

Bullough, V.L., 1994, Science in the bedroom. A history of sex research, Basic Books, New York.

Connell, B., 2003, The role of men and boys in achieving gender equality, viewed 10 March 2006, from http://www.un.org/ womenwatch/daw/egm/men-boys2003/Connell-bp.pdf.

Douglas, M., 1996 [1970], Natural symbols. Explorations in cosmology, Routledge, New York.

Douglas, M., 2004 [1966], Purity and danger. An analysis of concepts of pollution and taboo, Routledge, New York.

'Do you refuse to have sex?' 2008, Intimacy, July-September, 30-35.

Drakopoulou, M. (ed.), 2009, Reading law, reading women, Routledge, London.

Foucault, M., 1980, The history of sexuality. Volume 1: An introduction, transl. R. Hurley, Vintage Books, New York.

Grosz, E., 1994, Volatile bodies. Toward a corporeal feminism, Indiana University Press, Bloomington.

Hanafin, P., 2008, 'Voicing embodiment, relating difference: Towards a relational legal subjectivity', in M. Drakopoulou (ed.), Reading law, reading women, Routledge, London.

Hekma, G., 1991, 'A history of sexology: Social and historical aspects of sexuality', in J. Bremmer (ed.), From Sappho to de Sade. Moments in the history of sexuality, pp. 173-193, Routledge, London.

Hesse-Biber, S.N. \& Yaiser, M.L., 2004, Feminist perspectives on social research, Oxford University Press, New York.

Irigaray, L., 1985, Speculum of the other woman, transl. G.C. Gill, Cornell University Press, Ithaca.

Kometsi, K., 2004, (Un)Real. Aids review, CSA, Pretoria.

Laqueur, T., 1992, Making sex. Body and gender from the Greeks to Freud, Harvard University Press, Cambridge.

Maticka-Tyndale, E., Tiemoko, R. \& Makinwa-Adebusoye, P. (eds.), 2007, Human sexuality in Africa. Beyond reproduction, Fanele, Johannesburg.

Mirzoeff, N., 1995, Bodyscape. Art, modernity and the ideal figure, Routledge, New York.

Moore, L.J., 2007, Sperm counts. Overcome by man's most precious fluid, New York University Press, New York.

Morrell, R., 2001, 'The times of change. Men and masculinity in South Africa', in R. Morrell (ed.), Changing men in South Africa, pp. 3-37, University of Natal Press, Pietermaritzburg.

Morrell, R. (ed.), 2001, Changing men in South Africa, University of Natal Press, Pietermaritzburg.
Myerson, M., 1986, 'The politics of sexual knowledge: Feminism and sexology textbooks', Frontiers: A Journal of Women Studies 9(1), 66-71.

Peltzer, K., 2006, 'Sexuality among adolescents in rural and urban South Africa', South African Review of Sociology 37(2), 189-199.

Posel, D., 2005a, "'Baby rape": Unmaking secrets of sexual violence in post-apartheid South Africa', in G. Reid \& L. Walker (eds.), Men behaving differently. South African men since 1994, pp. 21-64, Double Storey Books, Cape Town.

Posel, D., 2005b, "The scandal of manhood: "Baby rape" and the politicization of sexual violence in post-apartheid South Africa', Culture, Health \& Sexuality 7(3), 239-252.

Reid, G. \& Walker, L., 2005, 'Editorial introduction. Sex and secrecy: A focus on African sexualities', Culture, Health $\mathcal{E}$ Sexuality 7(3), 185-194.

Reid, G. \& Walker, L. (eds.), 2005, Men behaving differently. South African men since 1994, Double Storey Books, Cape Town.

Reinharz, S., 1992, Feminist methods in social research, Oxford University Press, New York.

Sayers, J., 1986, Sexual contradictions. Psychology, psychoanalysis, and feminism, Tavistock, London.

Serrant-Green, L., 2005, 'Breaking traditions: Sexual health and ethnicity in nursing research: A literature review', Journal of Advanced Nursing 51(5), 511-519.

Sharpe, M. \& Faulkner, J., 2008, Understanding psychoanalysis, Acumen, Stocksfield.

Shoveller, J.A. \& Johnson, J.L., 2006, 'Risky groups, risky behaviour, and risky persons: Dominating discourses on youth sexual health', Critical Public Health 16(1), 47-60.

Smith, J.A., 2003, Qualitative psychology: A practical guide to research methods, Sage, London.

Sorrell, J.B.J. \& Raffaelli, M., 2005, 'An exploratory study of constructions of masculinity, sexuality and HIV/AIDS in Namibia, Southern Africa', Culture, Health $\mathcal{E}$ Sexuality 7(6), 585-598.

Sternberg, P., 2000, 'Challenging machismo: Promoting sexual and reproductive health with Nicaraguan men', in C. Sweetman (ed.), Gender in the 21st century, pp. 89-99, Oxfam, Oxford.

UNAIDS, 2006, Report on the global AIDS epidemic, UN, Geneva.

UNFPA, 2008, State of world population 2008. Reaching common ground. Culture, gender and human rights, viewed 1 December 2008, from http://www.unfpa.org/swp/.

Van der Kwaak, A. \& Dasgupta, J., 2006, 'Introduction: Gender and health', in A. Van der Kwaak \& M. Wegelin-Schuringa (eds.), Gender and health: Policy and practice. A global sourcebook, Oxfam, Oxford.

Van Dyk, A., 2001, Traditional African beliefs and customs: Implications for AIDS education and prevention in Africa, South African Journal of Psychology 31(2), 60-66.

Weeks, J., 1989, Sex, politics and society. The regulation of sexuality since 1800, Longman, New York.

WHO n.d., Sexual and reproductive health, viewed 20 November 2008, from http://www.who.int/reproductive-health/ gender/sexualhealth. html.

Wilkinson, S., 2003, 'Focus groups', in J.A. Smith (ed.), Qualitative psychology: A practical guide to research methods, pp. 184-204, Sage, London.

Wilkinson, S., 2004, 'Focus groups: A feminist method', in S.N. Hesse-Biber \& M.L. Yaiser (eds.), Feminist perspectives on social research, pp. 271-295, Oxford University Press, New York. 